\title{
When Mom has a Mental Illness: Role Reversal and Psychosocial Adjustment Among Emerging Adults
}

\author{
Kristen M. Abraham ${ }^{1,2}$ and Catherine H. Stein ${ }^{3}$ \\ ${ }^{1}$ University of Michigan \\ ${ }^{2}$ VA Center for Clinical Management Research, Serious Mental Illness Treatment Resource and \\ Evaluation Center \\ ${ }^{3}$ Bowling Green State University
}

Objective: Guided by a life course perspective, the present study examined whether aspects of the emerging adult-mother relationship, specifically affection, felt obligation, role reversal, and reciprocity, mediated the association between having a mother with mental illness and poorer psychological adjustment. Method: Emerging adults with mothers with mental illness $(n=52)$ and emerging adults without mothers with mental illness $(n=64)$ were recruited from institutes of higher education and responded to an online self-report questionnaire. Most participants $(81 \%)$ were female. Results: Results from multiple mediation analyses indicated a history of parent-child role reversal mediated the association between having a mother with mental illness and emerging adults' psychological symptoms. None of the assessed aspects of the emerging adult-mother relationship mediated the association between maternal mental illness and emerging adults' psychological well-being, but having divorced parents and being older was associated with lower levels of psychological well-being. Conclusions: Findings indicate role reversal contributes to emerging adults' psychological symptoms. Assessment of a history of role reversal may be relevant to clinical practice with emerging adults, particularly those with mothers with mental illness. Life course perspectives can inform future studies of emerging adults with mothers with mental illness. (c) 2013 Wiley Periodicals, Inc. J. Clin. Psychol. 69:600-615, 2013.

\section{Keywords: Maternal mental illness; role reversal; parentification; emerging adults}

Research conducted in nationally representative U.S. samples indicates that adult children remain connected to their parents across the life course (Lye, 1996). People with serious mental illness may be as likely as the general population to have children (Nicholson, Biebel, Hinden, Henry, \& Stier, 2001), but a remarkably small amount of research has focused on these individuals' emerging adult children. It is, however, well-documented that by the time they reach emerging adulthood, children of parents with serious mental illnesses of schizophrenia (Erlenmeyer-Kimling et al., 1997), bipolar disorders (DelBello \& Geller, 2001), and major depression (Klein, Lewinsohn, Rohde, Seeley, \& Olino, 2005) have more psychiatric and functioning difficulties than their counterparts whose parents do not have mental illness. Importantly, there is variability in functioning even among emerging adults characterized as "at risk" based on their parent's psychiatric status (Downey \& Coyne, 1990; Linnen, ann het Rot, Ellenbogen, \& Young, 2009; Mowbray, Bybee, Oyserman, MacFarlane, \& Bowersox, 2006). Biological contributions to psychological difficulties are undeniable. However, psychosocial factors, including relationships with parents, may also play a meaningful role in these emerging adults' psychological experiences (George, 2007). Unfortunately, to date, this has been a neglected area of study.

This research is partially based on the first author's dissertation, which was supported by a Dissertation Fellowship awarded by the Department of Psychology and Graduate College at Bowling Green State University. Writing of this manuscript was supported by the Office of Academic Affiliations, Advanced Fellowship Program in Mental Illness Research and Treatment, Department of Veterans Affairs.

Please address correspondence to: Kristen Abraham, 2800 Plymouth Road, University of Michigan North Campus Research Complex, Building 16, Floor 2- VA CCMR/SMITREC, Ann Arbor, MI 48109-2800. E-mail: abraham.kristen@gmail.com 
Scholars assert that life course perspectives are a useful framework in which to study family members of people with mental illness (Pickett, Cook, \& Cohler, 1994; Smith \& Greenberg, 2008; Stein \& Wemmerus, 2001). Although, "[t]here is no single, unified theory of the life course," a theoretical orientation of the life course includes several common principles that guide research in this framework (George, 1996, p. 249; Elder, 1994; Elder, Johnson, \& Crosnoe, 2003). One underlying element of life course research is the acknowledgement that family members' lives remain linked across the life span and influence one another (Elder, 1994; Elder et al., 2003). Life course perspectives are particularly relevant to people with serious mental illness and their families, because they also take into consideration interactions among social factors and mental illness and are thus useful in assessing potential pathways to psychological adjustment (George, 2007). Specifically, life course perspectives recognize that variations in individual outcomes are influenced by family interactions (Antonucci, Jackson, \& Biggs, 2007) as well as by norms and expectations tied to social roles (Pickett et al., 1994).

The present study seeks to expand the current literature on the emerging adult children of mothers with mental illness. We adopt a broad life course perspective to address the primary aim of the study-to assess whether aspects of the emerging adult-mother relationship mediate the established association between having a mother with mental illness and poorer psychological adjustment. To provide a context for the present study, we first review relationship constructs previously researched in the normative emerging adult-parent relationship (i.e., affection, felt obligation, and reciprocity) that may be associated with psychological adjustment (i.e., psychological symptoms or psychological well-being). These emerging adult-parent relationship constructs may also be relevant when parents have a mental illness. Second, we review the small body of extant literature on relationships between emerging adults and their parents with mental illness to identify additional relevant relationship constructs (i.e., role reversal).

\section{Relationships between Mothers and Emerging Adult Children: The Constructs of Affection, Felt Obligation, and Reciprocity}

Research and theory on adult children's relationships with their parents during emerging adulthood provides knowledge of the social norms for parent-child relationships during this phase of the life course. Developmental theory and research indicate that during emerging adulthood, children's relationships with their parents become more symmetrical, rather than hierarchical (Arnett, 2006; Youniss \& Smollar, 1985). Emerging adulthood is generally considered the developmental period from 18 to 25 years of age (Arnett, 2006), but it can be until 30 years of age before young persons have made the complete transition from emerging adulthood to young adulthood in terms of completing life course tasks and identity development (Arnett, 2000). Although emerging adults are more individuated from their parents than younger children, they also "maintain definite connections with their parents" (Youniss \& Smollar, 1985, p. 78). Moreover, it is generally emerging adults' relationships with their mothers (as compared with their fathers) that are considered close, mutual, and reciprocal (Youniss \& Smollar, 1985). More specifically, research indicates that the constructs of affection, felt obligation, and reciprocity characterize emerging adults' relationships with their parents and yield implications for the psychological adjustment of emerging adults.

Affection is considered a mechanism by which adult children's relationships with their parents are maintained across the lifespan (Lawton, Silverstein, \& Bengtson, 1994). Affection is generally defined as interpersonal bond and a sense of closeness and intimacy. Large-scale sociological demographic research indicates that adult children across the life course feel a high level of affection for their mothers (Lawton et al., 1994; Lye, 1996). Studies of emerging adults suggest they consider their relationships with their mothers to be affectionate, intimate, and comfortable (Buhl, 2008; Miller \& Lane, 1991; Miller \& Subblefield, 1993).

Felt obligation is similar to affection in that it is a relationally-based construct regarding how adult children feel toward their parents and is a mechanism through which adult children's relationships with their parents are maintained across the life course (Stein et al., 1998, Stein, 2009). However, felt obligation differs from affection in that it is a set of behaviors or actions (e.g., maintaining regular contact, be different than she is) that adults feel they "need to or 
should" perform in their relationships with their parents. Moreover, the felt obligation construct broadly captures the separateness and connectedness that are characteristic of emerging adults' relationships with their parents (Stein, 1992). Emerging and young adults report higher levels of felt obligation than do middle aged adults, suggesting that felt obligation is a construct that assesses developmental nuances in the adult child-parent relationship (Stein et al., 1998). Not surprisingly, research has consistently found that across developmental phases, felt obligation is higher toward mothers than fathers (Stein, 2009).

Reciprocity is considered a fundamental characteristic of the emerging adult-parent relationship representing the mutual and peer-like relationship between parents and children that typically begins in emerging adulthood (Wintre, Yaffe, \& Crowley, 1995; Youniss, 1980). In the emerging adult-parent relationship, mutual reciprocity includes respect for one another's points of view as well as involvement in open and ongoing communication (Wintre et al., 1995). Consistent with developmental theories (Arnett, 2006; Youniss, 1980), emerging adults report a higher degree of mutual reciprocity in their relationships with their parents than do adolescents (Wintre et al., 1995). Additionally, although not statistically assessed, emerging adults appear to experience higher levels of reciprocity with their mothers than their fathers (Wintre et al., 1995).

Life course perspectives acknowledge that family members' interactions may be associated with individuals' psychological adjustment (George, 2007). Affection, felt obligation, and reciprocity are interpersonal constructs that capture emerging adults' typical relationships with their mothers, and research indicates these constructs may play a meaningful role in emerging adults' psychological well-being. For example, longitudinal and cross-sectional studies find that, in general, closer bonds with parents are associated with better psychological well-being for emerging adults (Amato, 1994; Boutelle, Eisenberg, Gregory, \& Neumark-Sztainer, 2009; Roberts \& Bengtson, 1996; van Wel, ter Bogt, \& Raaijmakers, 2002).

Additionally, more reciprocity in the emerging adult-parent relationship is associated with fewer psychological symptoms in emerging adults (Agliata \& Renk, 2009). Although felt obligation has been studied in several samples of emerging adults (Abraham \& Stein, 2010; Stein, 2009), the relationship between felt obligation and psychological adjustment in emerging adults has not been extensively studied. In a small sample of emerging adults $(n=41)$, emerging adults' levels of felt obligation toward parents were not associated with psychological symptoms, well-being, and loneliness (Abraham \& Stein, 2010). However, in a sample of 502 adolescents, McAuliffe (2010) found that higher levels of some aspects of felt obligation toward mothers were associated with higher levels of psychological adjustment. Collectively, these findings suggest emerging adult-parent relationships that are characterized by higher levels of affection, reciprocity, and felt obligation may be associated with better psychological adjustment among emerging adults.

\section{Parental Mental Illness and the Emerging Adult-Parent Relationship}

Certainly, studies of young and adolescent children of parents with mental illnesses indicate that aspects of the parent-child relationship, such as parenting behaviors, are associated with children's psychological adjustment (Brenning, Soenens, Braet, \& Bal, 2011; Downey \& Coyne, 1990). However, the literature regarding interpersonal relationships between emerging adults and their parents with mental illness is remarkably scant. The sole quantitative study (Abraham \& Stein, 2010) that examined emerging adults' current relationships with their parents with mental illness found no differences in felt obligation between emerging adults with a mother or father with mental illness $(n=53)$ and parents without mental illness $(n=41)$, suggesting that emerging adults with parents with mental illness may not view their relationships with their parents differently than other emerging adults. However, this cross-sectional study also found that higher levels of felt obligation toward parents were associated with lower levels of psychological symptoms and loneliness among emerging adults who had a parent with mental illness whereas there had been no association between felt obligation and psychological adjustment among those with nondistressed parents.

Another quantitative study that addressed the association between historical aspects of the parent-child relationship and psychological adjustment found that perceived maternal support during childhood was associated with greater current life satisfaction among 61 emerging and 
young adults of mothers with affective disorders (Mowbray \& Mowbray, 2006). These studies provide some indication that current and historical aspects of the emerging adult-parent relationship are associated with psychological adjustment. Moreover, the findings suggest that higher quality relationships between parents and emerging adults could mitigate some of the psychological adjustment difficulties often experienced by emerging adults of parents with mental illness.

Qualitative and descriptive studies, although limited by small sample sizes, call attention to the complex nature of the current relationship between emerging adults and their parents with mental illness. Adult children report feelings of guilt, loyalty (Dunn, 1993), and anger toward their parent with mental illness (Williams, 1998). Additionally, qualitative and descriptive studies suggest parent-child role reversal may be commonly experienced. Caton and colleagues (1998) interviewed 39 adult children of parents with mental illness regarding their upbringing, and found that many recalled having to take over homemaking activities and provide care to their parent with mental illness. Similar recollections emerged in a sample of four adult women participating in a therapy group (Williams, 1998) and through interviews with nine adults (Dunn, 1993).

Role reversal, or parentification, is considered a structure of family roles that is characterized by a one-sided nature of exchange where children or adolescents assume the role of parenting their parents (Jurkovic, 1997). One empirical investigation (Alexander, 2003) examined role reversal among 832 emerging adults and found that paternal mental illness was associated with role reversal for sons but not daughters, and that maternal mental illness was not associated with role reversal for sons or daughters. However, the number of emerging adults who actually reported parents with mental illness in the Alexander (2003) study is not reported. Thus, the power to detect between-group differences and the generalizability of the findings is unknown.

Role reversal has not been extensively studied among emerging adults with parents with mental illness. However, empirical research demonstrates that emerging adult children who cope with other stressful circumstances, such as parental alcoholism (Kelley et al., 2007) and parental divorce (Jurkovic, Thirkield, \& Morrell, 2001) report higher levels of role reversal than their peers. Psychological adjustment correlates of role reversal have also been studied. A recent meta-analysis of 12 studies containing 2,472 participants found that experiencing higher levels of role reversal as children or adolescents was associated with more psychological symptoms in adulthood (Hooper, DeCoster, White, \& Voltz, 2011). Given the psychological adjustment difficulties of emerging adult children of people with mental illness and their experiences of role reversal as described in qualitative work, empirical examination of the association between role reversal and psychological adjustment in this population is needed.

\section{Present Study}

Guided broadly by a life course perspective, the aim of the present study was to assess whether aspects of the emerging adult-mother relationship mediated the association between the presence of maternal mental illness and poorer psychological adjustment. Mediation models allow for the assessment of whether a third intervening variable accounts for the relationship between an independent and dependent variable (MacKinnon, Fairchild, \& Fritz, 2007). Multiple mediation models extend the simple mediation model and simultaneously examine whether multiple intervening variables could account for a relationship between an independent and dependent variable (Preacher \& Hayes, 2008).

To address the aim and determine whether a mediation model was warranted, bivariate analyses were first conducted to assess the associations between (a) maternal mental illness and psychological adjustment, (b) maternal mental illness and emerging adult-mother relationship factors, and (c) emerging adult-mother relationship factors and psychological adjustment. It was hypothesized that aspects of the emerging adult-mother relationship would mediate the association between maternal mental illness and psychological adjustment, specifically that having a mother with mental illness would be associated with lower emerging adult-mother relationship quality (i.e., less affection and reciprocity, more role reversal), which, in turn, would be associated with poorer psychological adjustment (i.e., more psychological symptoms and lower psychological well-being). Given equivocal findings in prior research regarding whether 
felt obligation is associated with psychological adjustment, there was no specific hypothesis regarding the direction by which felt obligation might mediate the association between maternal mental illness and psychological adjustment.

\section{Method}

\section{Recruitment and Procedure}

Participants were recruited in conjunction with another study assessing the emerging adultmother relationship and caregiving for mothers with and without affective disorders (Abraham \& Stein, 2012). Participants were recruited from midwestern institutes of higher education through psychology department subject pools and instructor e-mails. To ensure an adequate sample size of emerging adults who self-identified as having a mother with mental illness, separate recruitment processes were used for the samples of emerging adults with and without mothers with mental illness. Recruitment scripts for emerging adults with mothers with mental illness invited participation from emerging adults whose mother was diagnosed with a serious mental illness (specifically schizophrenia, bipolar disorder, or major depression). Recruitment processes were similar for emerging adults without mothers with mental illness, except the recruitment scripts specified that having a mother with mental illness excluded participation. Participation was estimated to take less than 1 hour, and participation incentives included partial course credit (if available) and choice of entry into a raffle to win $\$ 50 \mathrm{gift}$ cards.

Online data collection methods were selected to obtain a larger sample of participants across several higher education institutions. Recruitment scripts contained an Internet link to the informed consent and survey. Prior studies in undergraduate samples suggest online methods of data collection yield responses equivalent to paper-and-pencil surveys regarding psychiatric symptoms (Coles, Cook, \& Blake, 2007; Naus, Philipp, \& Samsi, 2009) and other potentially sensitive information (e.g., trauma exposure; Read, Farrow, Jaanimägi, \& Ouimette, 2006). Participants completed the online informed consent and self-report questionnaire in a location of their convenience. Participants were not required to enter identifying information unless they wanted to obtain course credit or desired entry in the raffle. In these cases, participants were directed to a separate webpage where their name and e-mail address was entered. The identifying information was maintained in a database separate from the anonymous survey data, and both databases were located on a secure server. On the informed consent webpage, participants were provided with this information regarding data collection and storage. Additionally, they were informed of precautions they could take to minimize the risks inherent in completing any online survey (e.g., clear browser page history and cache). The research was approved by the appropriate institutional review boards.

A total of 211 emerging adults meeting the recruitment criteria responded to the online survey. To minimize the effects of potential confounding variables, data from four respondents were excluded for having a deceased father and from 91 respondents for reporting paternal mental illness and/or substance abuse. However, because the present study focused on maternal mental illness and participants' relationships with their mothers, data from respondents reporting maternal substance abuse $(n=22)$ were retained.

\section{Participants}

A total of 116 emerging adults, about half of who reported having a mother with mental illness $(n=52 ; 45 \%)$, participated in the present study. Participants were generally female $(n=94 ; 81 \%)$ and Caucasian $(n=106 ; 91 \%)$. Participants reported being a mean age of 19.79 years (standard deviation $[S D]=2.34$ ). Descriptive information regarding family context and maternal mental illness variables are presented in Table 1. Participants reporting no maternal mental illness or mothers with affective disorders were also participants in a separate study of the emerging adult-mother relationship and parental caregiving (Abraham \& Stein, 2012). 
Table 1

Family Context and Maternal Mental Illness Variables

\begin{tabular}{|c|c|c|c|c|c|}
\hline \multicolumn{3}{|c|}{ Frequency $(\%)$} & \multicolumn{2}{|c|}{ Frequency $(\%)$} & \multirow[t]{2}{*}{ Frequency $(\%)$} \\
\hline \multicolumn{5}{|l|}{ Family context } & \\
\hline Parents' marital status & & Maternal mental il & $\operatorname{less}^{\mathrm{a}}$ & Maternal substance abus & \\
\hline Married & $70(60)$ & Present & $52(45)$ & Present & $22(19)$ \\
\hline $\begin{array}{l}\text { Divorced/ } \\
\text { separated }\end{array}$ & $46(40)$ & Absent & $64(55)$ & Absent & $94(81)$ \\
\hline \multicolumn{4}{|l|}{ Maternal mental illness ${ }^{b}$} & Timing of Maternal & \\
\hline Diagnosis & & Diagnostician & & Mental Illness & Mean (SD) \\
\hline Depression & $28(54)$ & Mental health & $19(37)$ & Age of young adult at & $\overline{10.50(5.44)}$ \\
\hline Bipolar disorder & $18(35)$ & Professional & & time of diagnosis ${ }^{\mathrm{c}}$ & \\
\hline Schizophrenia & $3(6)$ & Family doctor & $6(12)$ & & Frequency $(\%)$ \\
\hline $\begin{array}{l}\text { Schizoaffective } \\
\text { disorder }\end{array}$ & $1(2)$ & "I don't know" & $27(52)$ & $\begin{array}{l}\text { Before young adult } \\
\text { born }\end{array}$ & $8(15)$ \\
\hline \multirow[t]{3}{*}{ Other } & $2(4)$ & & & $\begin{array}{l}\text { After young adult } \\
\text { born }\end{array}$ & $30(58)$ \\
\hline & & Suicide attempt & & "I don’t know" & $14(27)$ \\
\hline & & Yes & $8(15)$ & & \\
\hline Yes & $44(85)$ & No & $42(81)$ & & Mean (SD) \\
\hline No & $8(15)$ & No response & $2(4)$ & $\begin{array}{l}\text { Psychiatric } \\
\text { hospitalizations }^{\mathrm{d}}\end{array}$ & $\overline{1.10(2.07)}$ \\
\hline
\end{tabular}

Note. $\mathrm{SD}=$ standard deviation.

${ }^{\text {a }}$ Participants reporting a mother with mental illness were more likely to be male, $X^{2}(1, \mathrm{~N}=116)=5.99$, $p<.05$, report maternal substance abuse, $X^{2}(1, \mathrm{~N}=116)=8.54, p<.01$, have divorced/separated parents, $X^{2}(1, \mathrm{~N}=116)=10.23, p=.001$, and were marginally more likely to be Persons of Color, $X^{2}(1, \mathrm{~N}=116)$ $=2.80, p=.09$, than participants without mothers with mental illness.

${ }^{\mathrm{b}}$ Only participants who reported having a mother with mental illness $(n=52)$ provided information regarding maternal mental illness.

${ }^{\mathrm{c}}$ Includes only participants who reported their mothers were diagnosed after their birth $(n=30)$.

${ }^{\mathrm{d}}$ Two participants did not report number of psychiatric hospitalizations $(n=50)$.

\section{Measures}

Maternal mental illness. The single-item question: "Has your mother been diagnosed with a mental illness?" was used to assess maternal mental illness. This method of ascertaining parental mental illness from emerging adults' reports has been used previously (Abraham \& Stein, 2010). Participants who responded affirmatively to this item were prompted to provide additional information regarding their mother's mental illness. Questions regarding maternal mental illness were adapted from Alexander (2003), whose assessment of maternal mental illness included respondents' reports of whether mothers had received medication or been hospitalized for a psychiatric diagnosis and whether mothers had ever attempted suicide. In the present study, additional questions regarding mothers' psychiatric diagnosis and number of psychiatric hospitalizations were added to capture a broader understanding of mothers' mental health status.

Maternal substance abuse. Maternal substance use was assessed by the following questions: (a) "Has your mother ever had a problem with drinking?" and (b) "Has your mother ever had a problem with drugs?" Substance abuse was assumed if participants responded affirmatively to either or both questions. This operational definition of maternal substance abuse was adapted from Cuijpers and Smit's (2001) single-item method of assessing parental alcoholism from emerging adults' reports. Research indicates using a single-item question to assess parental alcoholism yields results comparable to lengthier methods (i.e., Family History Research 
Table 2

Descriptive Statistics for Study Measures

\begin{tabular}{|c|c|c|c|c|}
\hline Measure & Items & Response Anchors & Mean (SD) & Cronbach's $\alpha$ \\
\hline $\begin{array}{l}\text { Parental Perception of Reciprocity } \\
\text { scale }^{\text {a }}\end{array}$ & 17 & $\begin{array}{l}0 \text { (Strongly Disagree) to } 5 \text { (Strongly } \\
\quad \text { Agree) }\end{array}$ & $3.14(1.20)$ & .94 \\
\hline Positive Affect Index (modified) & 6 & 1 (Not at All) to 6 (Extremely) & $4.62(1.27)$ & .93 \\
\hline Felt Obligation Measure ${ }^{a}$ & 34 & 1 (Rarely) to 5 (Very Often) & $3.56(.76)$ & .95 \\
\hline Relationship with Parents scale ${ }^{a}$ & 21 & $\begin{array}{l}1 \text { (Strongly Disagree) to } 5 \text { (Strongly } \\
\quad \text { Agree) }\end{array}$ & $2.37(.84)$ & .93 \\
\hline $\begin{array}{l}\text { Brief Symptom Inventory- General } \\
\text { Severity Index }\end{array}$ & 53 & 0 (not at all) to 4 (extremely) & $.86(.77)^{\mathrm{b}}$ & .97 \\
\hline Schwartz Outcomes scale & 10 & $\begin{array}{l}0 \text { (Never) to } 6 \text { (Nearly all of the } \\
\text { time) }\end{array}$ & $4.24(1.19)^{\mathrm{c}}$ & .93 \\
\hline
\end{tabular}

Note. $\mathrm{SD}=$ standard deviation.

${ }^{a}$ Mother version of the measure.

${ }^{b}$ Relative to a prior study (Cochran \& Hale, 1985), present study participants reported significantly higher levels of symptoms than a sample of college student women, but did not significantly differ in their reports of symptoms as compared to a sample of college student men (analyses not shown).

${ }^{c}$ Relative to a prior study (Young, Waehler, Laux, McDaniel, \& Hilsenroth, 2010), present study participants reported significantly lower levels of psychological well-being than a sample of college students (analyses not shown).

Diagnostic Criteria) of assessing parental alcoholism from emerging adults' reports (Cuijpers \& Smit, 2001).

Relationship reciprocity. The Perception of Parental Reciprocity Scale (MOPRS; mother subscale) assessed emerging adults' perceived communication reciprocity in their relationships with their mothers (Wintre et al., 1995). A sample item of the MOPRS is "I can communicate with my mother as I can with my friends." Higher scores indicate more reciprocity. Evidence of convergent validity of the MOPRS includes positive associations with measures of attachment and attitudes toward authority. Evidence of discriminate validity of the MOPRS includes a lack of relationship with a measure of self-esteem (Wintre et al., 1995). The measure demonstrated good internal consistency $(\alpha=.93)$ in a sample of college students (Renk, Donnelly, Klein, Oliveros, \& Baksh, 2008). Table 2 contains the scale anchors, and the internal reliability coefficient, mean and standard deviation of this measure and all other study measures in the present study's sample.

Affection. A modified version of the Positive affect Index (Bengtson \& Schrader, 1982) was used to assess emerging adults' affection for their mothers. Higher scores are indicative of higher levels of affection. The original measure contains five items that assess emerging adults' feelings toward their mothers and five items that assess emerging adults' perceptions of their mothers' feelings toward them. Because only emerging adults' feelings of affection were the construct of interest, only the five items tapping this construct were used in the present study. Amato (1994) used a similarly modified version of the Positive Affect Index. Good internal consistency $(\alpha=$ .89) for the original measure was found in a sample of college students (Bengtson \& Schrader, 1982).

Felt obligation. Emerging adults' feelings of obligation toward their mothers were assessed by the Felt Obligation Measure (FOM; Stein, 1992). This self-report measure includes five interrelated dimensions; however, a total score for the FOM, which broadly captures the separateness and connectedness characteristic of adult child-parent relationships, was selected for the present study for parsimony. Higher scores on the FOM indicate higher levels of felt obligation. Evidence for convergent validity of the FOM is 
demonstrated by its relationships to measures of filial responsibility, affection toward and frequency of contact with parents. A lack of significant relationship between the FOM and social desirability provides evidence of discriminate validity (Stein, 1992). In a prior sample of emerging adults, internal consistency for the felt obligation toward mothers measure was good $(\alpha=$ .94; Freeberg \& Stein, 1996).

Parent-child role reversal. The Relationship with Parents scale-mother version (Alexander, 2003) was used to assess emerging adults' perceptions of role reversal in their childhood relationship with their mothers. Items reflect emerging adults' retrospective accounts of their mothers using guilt to elicit nurturing from them, demanding their attention or company, and their perception of their mothers' competence as a parent. Higher scores indicate a higher degree of role reversal. Alexander (2003) reports initial convergent validity, good internal consistency $(\alpha=.86)$ and adequate test-retest reliability ( $r=.82$ for men; $r=.88$ for women) for the measure in a sample of 990 emerging adults. Evidence of validity for the Relationship with Parents scale includes its relationship to a measure of family cohesion, such that higher cohesiveness among all family members was related to lower role reversal, and alignment with the mother against the father was associated with more mother-child role reversal.

Psychological symptoms. The Brief Symptom Inventory (Derogatis, 1993; Derogatis \& Melisaratos, 1983), a widely used self-report symptom checklist, was used to assess participants' psychological symptoms. The General Severity Index (GSI) accounts the intensity and number of a broad range of psychological symptoms within the past week, thus higher scores indicate a greater number and intensity of psychological symptoms (Derogatis \& Melisaratos, 1983). Test-retest reliability for the GSI was high $(r=.90)$ and the measure is highly correlated with the Symptom Checklist-90, the longer version of the BSI (Derogatis, 1993). Internal consistency of the GSI is high $(\alpha=.90$; Derogatis $\&$ Spencer, 1982).

Psychological well-being. Participants' self-reported global psychological well-being over the past week was assessed with the Schwartz Outcomes Scale (SOS-10; Blais et al., 1999), a single dimension measure of broad psychological health. Higher scores are indicative of more well-being. Evidence for convergent validity includes strong negative relationships with various measures of psychiatric symptoms and strong positive relationships with measures of general well-being, positive affect, and self-esteem (Blais et al., 1999). Further research indicates convergent validity for the SOS-10, as it is associated with interpersonal well-being (Haggerty, Blake, Naraine, Siefert, \& Blais, 2010). Internal consistency of the scale was excellent $(\alpha>.90)$ in three independent samples (i.e., psychiatric inpatients, psychiatric outpatients, nonpatients; Blais et al., 1999).

\section{Results}

\section{Preliminary Analyses}

To determine whether mediation analyses were warranted, Pearson bivariate correlations (Table 3) were first conducted to assess bivariate relationships between (a) maternal mental health status and emerging adults' psychological adjustment, (b) maternal mental health status and the emerging adult-mother relationship characteristics, and (c) emerging adult-mother relationship characteristics and emerging adults' psychological adjustment. At the bivariate level, having a mother with mental illness was associated with higher levels of psychological symptoms $(r=$ $.32, p<.01)$ and lower levels of psychological well-being $(r=-.25, p<.01)$.

Having a mother with mental illness was also associated with higher levels of role reversal, and lower levels of affection, reciprocity, and felt obligation $(r \mathrm{~s}=|.28|$ to $|.49|, p \mathrm{~s}<.01)$. A prior study using a subsample of the present sample found comparable bivariate results between maternal mental illness and the emerging adult-mother relationship-having a mother with an affective disorder was associated with lower levels of affection, reciprocity, felt obligation, and reciprocity (Abraham \& Stein, 2012). 
Table 3

Pearson Bivariate Correlation Matrix of Study Variables

\begin{tabular}{|c|c|c|c|c|c|c|c|c|c|c|c|c|}
\hline & 1 & 2 & 3 & 4 & 5 & 6 & 7 & 8 & 9 & 10 & 11 & 12 \\
\hline 1. Age & - & & & & & & & & & & & \\
\hline 2. Gender ${ }^{\mathrm{a}}$ & -.05 & $\ldots$ & & & & & & & & & & \\
\hline $\begin{array}{l}\text { 3. Maternal mental } \\
\text { illness }^{\mathrm{b}}\end{array}$ & .14 & $-.23^{*}$ & - & & & & & & & & & \\
\hline $\begin{array}{l}\text { 4. Maternal } \\
\text { substance abuse }\end{array}$ & .04 & $-.22 *$ & $.27 * *$ & - & & & & & & & & \\
\hline $\begin{array}{l}\text { 5. Parental martial } \\
\text { status }^{\mathrm{c}}\end{array}$ & -.05 & -.03 & $-.30^{* *}$ & $-.28^{* *}$ & - & & & & & & & \\
\hline $\begin{array}{l}\text { 6. Maternal } \\
\text { hospitalizations } \mathrm{d}\end{array}$ & -.10 & .10 & - & $.38 * *$ & -.22 & - & & & & & & \\
\hline 7. Affection & $-.27 * *$ & $=.18$ & $-.49 * *$ & $-.44 * *$ & $.39 * *$ & -.21 & - & & & & & \\
\hline 8. Felt obligation & $-.31 * *$ & $.19 *$ & $-.28 * *$ & $-.30 * *$ & $.19 *$ & -.06 & $.67 * *$ & - & & & & \\
\hline 9. Role reversal & .13 & -.11 & $.38 * *$ & $.26^{* *}$ & $-.39 * *$ & .15 & $-.34 * *$ & -.17 & - & & & \\
\hline 10. Reciprocity & $-.26 * *$ & $.25^{* *}$ & ${ }^{*}-.46^{* *}$ & $-.33 * *$ & $.29 * *$ & -.21 & $.85^{* *}$ & $.65^{* *}$ & $*-.34 * *$ & - & & \\
\hline $\begin{array}{l}\text { 11. Psychological } \\
\text { symptoms }\end{array}$ & .08 & -.13 & $.32 * *$ & $.29 * *$ & $-.32 * *$ & $-.02-$ & $-.32 * *$ & -.09 & $.48^{* *}$ & $-.29 * *$ & - & \\
\hline $\begin{array}{l}\text { 12. Psychological } \\
\text { well-being }\end{array}$ & $-.25^{* *}$ & .08 & $-.25^{* *}$ & $-.21^{*}$ & $.34 * *$ & -.05 & $.33^{* *}$ & $.27 * *$ & $*-.20 *$ & $.27^{* *}$ & $-.59 * *$ & * \\
\hline
\end{tabular}

Note. $N=116$.

${ }^{\mathrm{a}}$ female $=1$, male $=0$.

$\mathrm{b}_{\text {condition present }}=1$, condition absent $=0$.

${ }^{\mathrm{c}}$ married $=1$, divorced $/$ separated $=0$.

${ }^{\mathrm{d}}$ Only participants with mothers with mental illness responded to this measure, and two participants with mothers with mental illness did not report their mother's number of hospitalizations $(n=50)$.

$* * p<.01 . * p<.05$.

With one exception, aspects of the emerging adult mother relationship were significantly associated with psychological symptoms and well-being $(r \mathrm{~s}=|.20|$ to $|.48|, p \mathrm{~s}<.05)$. Felt obligation was not significantly associated with psychological symptoms $(r=-.09, p>.05)$. Thus, at the bivariate level, maternal mental illness was associated with psychological adjustment, maternal mental illness was associated with the emerging adult-mother relationship, and the emerging adult-mother relationship was associated with psychological adjustment.

\section{Psychological Symptoms and Psychological Well-Being}

To address the aim of the study, bootstrapping multiple mediation methods (Preacher \& Hayes, 2008) were used to assess whether aspects of the emerging adult-mother relationship could account for the association between maternal mental illness and poorer psychological adjustment. This approach to mediation was selected over Sobel's $(1982,1986)$ estimated standard error method and Baron and Kenny's (1986) causal steps method because, when using bias-corrected and accelerated confidence (BCa) intervals, it has higher power to detect mediated effects, does not require large samples (Fritz \& MacKinnon, 2007) or assume normality of the sampling distribution (Hayes, 2009), and yields acceptable control over type I error (MacKinnon, Lockwood, \& Williams, 2004). Using Preacher and Hayes's (2008) macro for the Statistical Package for the Social Sciences (SPSS), 1,000 bootstrap samples were drawn to construct BCa confidence intervals to estimate the total indirect (i.e., mediation) effect of all relationship factors (i.e., affection, role reversal, felt obligation, reciprocity) and the specific indirect (i.e., mediation) effect of each individual relationship factor while controlling for the other relationship factors. An indirect effect is considered significant if the confidence interval does not contain zero, as this demonstrates the estimate of the effect is significantly different from zero (Preacher \& Hayes, 2008). 


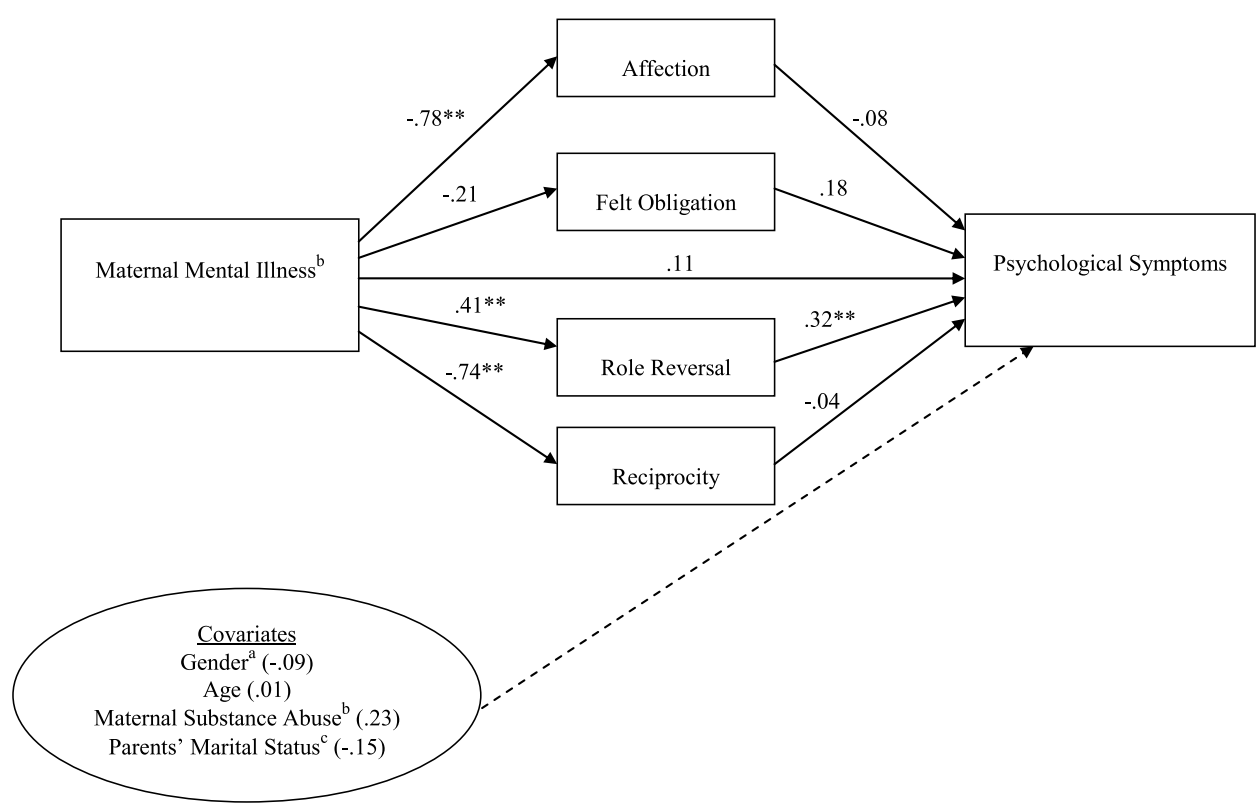

Figure 1. Mediator Model: Effect of Maternal Mental Illness on Psychological Symptoms through Relationship Factors.

Note. Path values represent unstandardized regression coefficients. Covariate values represent the unstandardized regression coefficients in the full model. $* p<.05 . * * p<.01$.

${ }^{\mathrm{a}}$ female $=1$, male $=0 ;{ }^{\mathrm{b}}$ condition present $=1$, condition absent $=0 ;{ }^{\mathrm{c}}$ married $=1$, divorced $/$ separated $=$ 0 .

Two multiple meditational analyses were conducted with maternal mental illness as the independent variable, and the four emerging adult-mother relationship factors as potential mediators. In one analysis, participants' psychological symptoms served as the dependent measure, and in the other analysis participants' overall psychological well-being was the dependent measure. In both models, demographic and family context variables of gender, age, parents' marital status, and maternal substance abuse status were entered as covariates.

In the model with psychological symptoms as the dependent variable (Figure 1), there was a collective indirect effect for the aspects of the emerging adult-mother relationship, $95 \% \mathrm{BCa}$ confidence interval $[\mathrm{CI}](.0227, .4059)$. Of the four emerging adult-mother relationship factors, the only significant indirect effect was for role reversal, 95\% BCa CI $(.0361, .3320)$, indicating that role reversal mediated the association between maternal mental illness and psychological symptoms. Having a mother with mental illness was associated with higher levels of role reversal, which, in turn, was associated with higher levels of psychological symptoms. In the mediation model the direct effect of maternal mental illness was not significant. Overall, the full model was significant, $F(9,106)=5.12, p<.00001, R^{2}=.30$, Adj. $R^{2}=.24$.

In the model with psychological well-being as the dependent measure, neither the collective indirect effect of all emerging adult-mother relationship factors nor any of the individual relationship factors significantly mediated the association between maternal mental illness and psychological well-being (Figure 2). However, the full regression model was significant, $F(9$, $106)=3.09, p<.01, R^{2}=.21$, Adj. $R^{2}=.14$, and only the covariates of age $(\beta=-.19, p<$ $.05)$ and parents' marital status $(\beta=.24, p<.05)$ were significant predictors of psychological well-being. Specifically, being younger and having married parents were associated with higher levels of psychological well-being.

\section{Discussion}

Guided by a life course perspective, the aim of the present study was to examine whether emerging adults' self-reported affection, felt obligation, reciprocity, and role reversal in their 


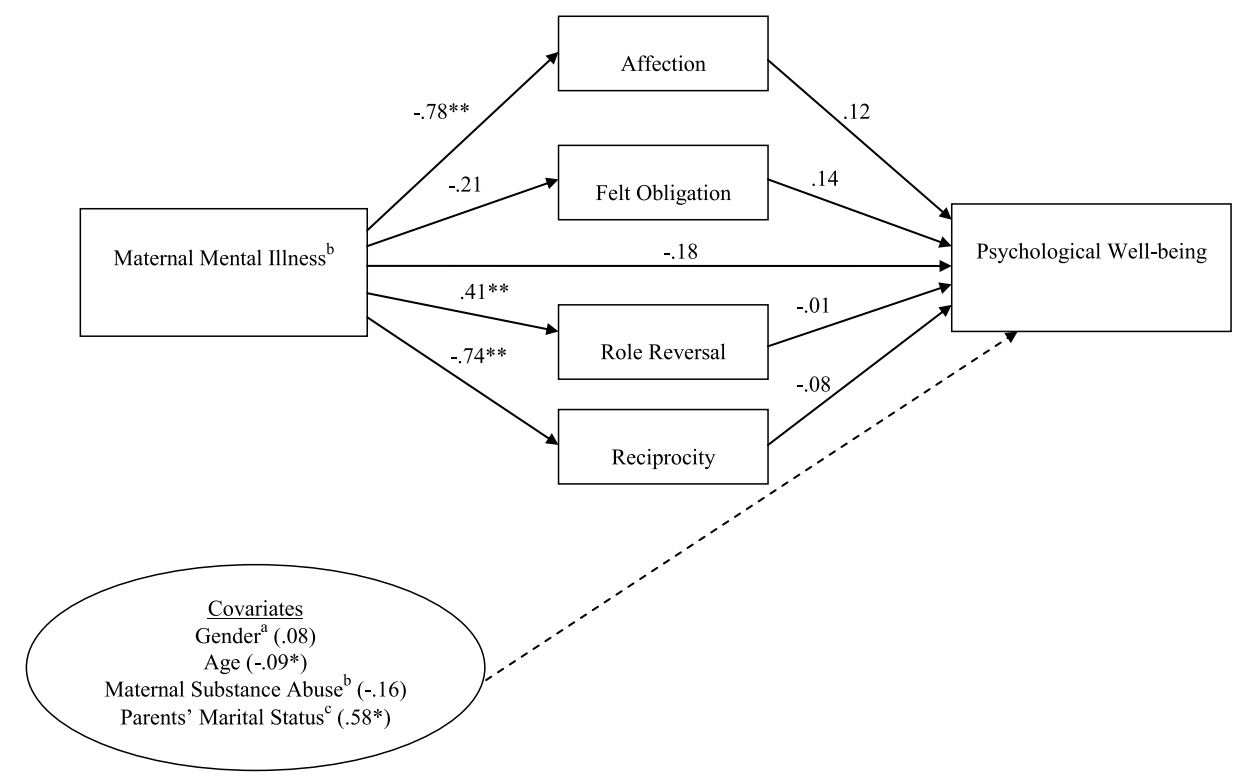

Figure 2. Mediator Model: Effect of Maternal Mental Illness on Psychological Well-being through Relationship Factors.

Note. Path values represent unstandardized regression coefficients. Covariate values represent the unstandardized regression coefficients in the full model. $* p<.05 . * * p<.01$.

${ }^{\mathrm{a}}$ female $=1$, male $=0 ;{ }^{\mathrm{b}}$ condition present $=1$, condition absent $=0 ;{ }^{\mathrm{c}}$ married $=1$, divorced $/$ separated $=$ 0 .

relationships with their mothers mediated the association between maternal mental illness and emerging adults' psychological adjustment. Findings indicate role reversal mediated the association between maternal mental illness and psychological symptoms. Maternal mental illness was associated with higher levels of role reversal, which, in turn, was associated with higher levels of psychological symptoms. This mediation effect is consistent with prior qualitative and descriptive research, which found that role reversal was a common experience of young and emerging adults who cope with parental mental illness (Caton et al., 1998; Dunn, 1993; Williams, 1998) and with a meta-analysis which found higher levels of a history of role reversal were associated with more psychological difficulties (Hooper et al., 2011).

The present study expanded the prior literature by shedding light on a mechanism, role reversal, by which emerging adults affected by maternal mental illness experience higher levels of psychological symptoms than their peers. Life course research indicates that family members of people with serious mental illness experience psychological consequences associated with their family member being "off time" (Pickett et al., 1994; Stein \& Wemmerus, 2001). "Off timedness" refers to difficulties attaining normative social roles or challenges maintaining the normative expectations associated them. By definition, role reversal is a structural shift in the normative social roles of parent and child. A history of parent-child role reversal, which was more common among emerging adults with mothers with mental illness, may represent life course disruption that yields psychological consequences.

Present study findings also indicated that none of the assessed emerging adult-mother relationship constructs mediated the association between maternal mental illness and psychological well-being. In addition, after controlling for significant effects for age and parental divorce, there was no significant direct effect for maternal mental illness on overall psychological wellbeing. Consistent with a life course framework, this underscores the importance of assessing demographic and family context variables when examining psychological well-being among emerging adults. The association between parental divorce and poorer psychological well-being is consistent with much prior research that parental divorce is associated with less life satisfaction (see Amato \& Keith, 1991, for a meta-analysis). The finding of increasing age being 
associated with poorer psychological well-being is surprising given that psychological well-being generally increases during emerging adulthood (Arnett, 2007; Schulenberg, O'Malley, Bachman, \& Johnston, 2005). The present study finding may be attributable to the age range of the sample being 18-30 years of age, whereas large-scale investigations (Arnett, 2007; Schulenberg et al., 2005) of well-being in emerging adulthood have focused on the 18-24 years of age range. Future research in emerging and young adult samples is needed to determine whether the present finding is replicable or the result of random sampling variation.

The different findings in the mediation analyses predicting psychological symptoms and psychological well-being also warrant attention. The present study found a moderate bivariate association between psychological symptoms and psychological well-being, but different correlates within the mediation analyses for psychological adjustment and psychological wellbeing. Consistent with research and theory (Diener \& Emmons, 1984; Watson \& Tellegen, 1985; Watson, Weise, Vaidya, \& Tellegen, 1999), this suggests that positive psychological experiences (e.g., well-being) and negative psychological experiences (e.g., symptoms) are not mutually exclusive experiences. While positive and negative psychological experiences may share some variance, they do not necessarily reflect a single underlying construct. Furthermore, the results of the mediation analyses are consistent with research demonstrating that the pathways by which individuals experience positive and negative affect can be different (Gruenewald, Mroczek, Ryff, \& Singer, 2008).

Finally, contrary to the hypotheses the relationship constructs of affection and reciprocity did not mediate the association between maternal mental illness and psychological adjustment. Emerging adults with mothers with mental illness did report a lower degree of affection and reciprocity in their relationships with their mothers. However, in multivariate models affection and reciprocity were not associated with psychological adjustment. Future studies are needed to identify whether other relationship constructs could be associated with improved psychological adjustment among emerging adults with mothers with mental illness.

\section{Study Limitations}

Although the findings of the present study are compelling, they are preliminary and methodological limitations warrant discussion. Primarily, generalizability of findings is limited by the relatively small study sample of predominately Caucasian, emerging adult college students whose self-reports were used to assess their mother's mental health status. Additionally, emerging adults' reports of their mother's mental illness ascertained through a single-item may not be accurate, particularly with regard to assessing undiagnosed psychiatric problems. Despite this, emerging adults' self-identification as having a mother with mental illness is relevant in that it reflects their perception of their own experience. Methodological improvements including recruiting larger, more diverse samples and obtaining diagnostic verification of parental mental illness from psychiatric records or parents' reports will strengthen future studies.

Another limitation of the present study is the cross-sectional design that, of course, makes it impossible to infer causality among the variables. Particular caution must be used because mediation models examine proposed mechanisms of causality (Preacher \& Hayes, 2008). Results of the present study can best be interpreted as elucidating factors that play a role in the psychological adjustment of emerging adults with mothers with mental illness. Longitudinal research designs of emerging adults with and without mothers with mental illness will be critical to understanding whether role reversal plays a causal mechanism in the development of psychological symptoms.

Certainly, the assessment of emerging adults' interpersonal relationship characteristics in the present study is not exhaustive. As the aim of the present study was to examine whether aspects of the emerging adult-mother relationship were associated with psychological adjustment, emerging adults' perception of social support, from their mothers or other sources including friends and other family members, was not specifically assessed. However, a small study (Williams \& Corrigan, 1992) found that size and satisfaction with one's social support network mitigated psychological symptoms among emerging adults of parents with mental illness. Of interest to life course researchers is understanding of pathways and mechanisms that lead to psychological 
symptoms and well-being (George, 2007). Future research should more thoroughly examine the mediating or moderating effects of social support from various sources on the psychological adjustment of emerging adults affected by maternal mental illness.

\section{Implications for Research and Clinical Practice}

Limitations notwithstanding, the results of the present study yield useful information for future research and clinical practice. The present study was among the first to examine the emerging adults' perceptions of their relationships with their mothers with mental illness, and found that role reversal, a historical aspect of the parent-child relationship, is associated with emerging adults' current psychological adjustment. Future research is needed to understand whether and how the experience of maternal mental illness and parent-child role reversal is associated with adult children's transitions into different life course stages, such as young adulthood and middle adulthood, as well as their adoption of social roles such as spouse, employee, and parent. Life course perspectives are particularly useful in understanding transitions and trajectories of individuals in the context of their social and family lives and are appropriate for the study of family members of people with mental illness (Cook et al., 1994; Smith \& Greenberg, 2008; Stein \& Wemmerus, 2001). Psychologists should consider how life course perspectives can be adopted to inform future research on the emerging adult children of people with mental illness.

Finally, although assessing a family history of mental illness is common in psychological evaluations, the present study suggests that it is also the presence of role reversal, rather than solely the presence of maternal mental illness, which is associated with increased psychological symptoms. A most basic implication for clinical practice is that an assessment of whether or not emerging adults experienced role reversal is relevant to their psychological functioning (see also Hooper et al., 2011). Researchers should examine whether existing measures of role reversal or parentification (e.g., Alexander, 2003; Jurkovic \& Thirkield, 1998) would be useful in clinical practice.

\section{Conclusions}

The present study is a preliminary examination of whether affection, felt obligation, role reversal, and reciprocity in the emerging adult-mother relationship mediated the association between having a mother with mental illness and poorer psychological adjustment. Findings point to role reversal as a mediator of the effects of maternal mental illness on emerging adults' psychological symptoms. Continued research examining possible psychosocial mechanisms that contribute to variation in psychological adjustment will help develop clinical interventions to promote well-being for emerging adults who cope with parental mental illness.

\section{References}

Abraham, K. M., \& Stein, C. H. (2010). Staying connected: Young adults' felt obligation toward parents with and without mental illness. Journal of Family Psychology, 24, 125-134.

Abraham, K. M., \& Stein, C. H. (2012). Emerging adults' perspectives on their relationships with mothers with mental illness: Implications for caregiving. American Journal of Orthopsychiatry, 82, 542-549.

Agliata, A. K., \& Renk, K. (2009). College students' affective distress: The role of expectation discrepancies and communication. Journal of Child and Family Studies, 18, 396-411.

Alexander, P. C. (2003). Parent-child role reversal: Development of a measure and test of an attachment theory model. Journal of Systemic Therapies, 22, 31-44.

Amato, P. R. (1994). Father-child relations, mother-child relations, and offspring psychological well-being in early adulthood. Journal of Marriage and Family, 56, 1031-1042.

Amato, P. R., \& Keith, B. (1991). Parental divorce and adult well-being: A meta-analysis. Journal of Marriage and Family, 53, 43-58.

Antonucci, T. C., Jackson, J. S., \& Biggs, S. (2007). Intergenerational relations: Theory, research, and policy. Journal of Social Issues, 63, 679-693. 
Arnett, J. J. (2000). Emerging adulthood: A theory of development from the late teens through the twenties. American Psychologist, 55, 469-480.

Arnett, J. J. (2006). Emerging adulthood: The winding road from the late teens through the twenties. New York, NY: Oxford University Press.

Arnett, J. J. (2007). Emerging adulthood: What is it, and what is it good for? Child Development Perspectives, $1,68-73$.

Baron, R. M., \& Kenny, D. A. (1986). The moderator-mediator variable distinction in social psychological research: Conceptual, strategic, and statistical considerations. Journal of Personality and Social Psychology, 51, 1173-1182.

Bengtson, V. L., \& Schrader, S. (1982). Parent-child relations. In D. Mangen \& W. A. Peterson (Eds.), Research instruments in social gerontology (Vol. 2, pp. 115-186). Minneapolis, MN: University of Minnesota Press.

Blais, M. A., Lenderking, W. R., Baer, L., deLorell, A., Peets, K., Leahy, L., \& Burns, C. (1999). Development and initial validation of a brief mental health outcome measure. Journal of Personality Assessment, 73, 359-373.

Boszormenyi-Nagy, I., \& Spark, G. M. (1973). Invisible loyalties: Reciprocity in intergenerational family therapy. Hagerstown, MD: Harper \& Row.

Boutelle, K., Eisenberg, M. E., Gregory, M. L., \& Neumark-Sztainer, D. (2009). The reciprocal relationship between parent - child connectedness and adolescent emotional functioning over 5 years. Journal of Psychosomatic Research, 66, 309-316.

Brenning, K., Soenens, B., Braet, C., \& Bal, S. (2011). The role of parenting and mother-adolescent attachment in the intergenerational similarity of internalizing symptoms. doi 10.1007/s10964-0119740-9.

Buhl, H. M. (2008). Development of a model describing individuated adult child-parent relationships. International Journal of Behavioral Development, 32, 381-389.

Caton, C. L. M., Cournos, F., Felix, A., \& Wyatt, R. J. (1998). Childhood experiences and current adjustment of offspring of indigent patients with schizophrenia. Psychiatric Services, 49, 86-90.

Cochran, C. D., \& Hale, W. D. (1985). College student norms on the Brief Symptom Inventory. Journal of Clinical Psychology, 41, 777-779.

Coles, M. E., Cook, L. M., \& Blake, T. R. (2007). Assessing obsessive compulsive symptoms and cognitions on the internet: Evidence for the comparability of paper and internet administration. Behaviour Research and Therapy, 45, 2232-2240.

Cuijpers, P., \& Smit, F. (2001). Assessing parental alcoholism: A comparison of the Family History Research Diagnostic Criteria versus a single-question method. Addictive Behaviors, 26, 741-748.

DelBello, M. P., \& Geller, B. (2001). Review of studies of child and adolescent offspring of bipolar parents. Bipolar Disorders, 3, 325-334.

Derogatis, L. R. (1993). Brief symptom inventory: Administration, scoring, and procedures manual. Bloomington, MN: Pearson.

Derogatis, L. R., \& Melisaratos, N. (1983). The brief symptom inventory: An introductory report. Psychological Medicine, 13, 595-605.

Derogatis, L. R., \& Spencer, P. M. (1982). Administration and procedures: BSI. Manual Baltimore, MD: Clinical Psychometric Research.

Diener, E., \& Emmons, R. A. (1984). The independence of positive and negative affect. Journal of Personality and Social Psychology, 47, 1105-1117.

Downey, G., \& Coyne, J. C. (1990). Children of depressed parents: An integrative review. Psychological Bulletin, 108, 50-76.

Dunn, B. (1993). Growing up with a psychotic mother: A retrospective study. American Journal of Orthopsychiatry, 63, 177-189.

Elder, G. (1994). Time, human agency, and social change: Perspectives on the life course. Social Psychology Quarterly, 57, 4-15.

Elder, G. H., Johnson, M. K., \& Crosnoe, R. (2003). The emergence and development of life course theory. In J. T. Mortimer, \& M. J. Shanahan (Eds.), Handbook of the life course (pp. 3-19). New York, NY: Kluwer Academic/Plenum.

Erlenmeyer-Kimling, L., Adamo, U. H., Rock, D., Roberts, S. A., Bassett, A. S., Squires-Wheeler, E., ... Gottesman, I. I. (1997). The New York high-risk project: Prevalence and comorbidity of axis I 
disorders in offspring of schizophrenic parents at 25-year follow-up. Archives of General Psychiatry, 54, 1096-1102.

Freeberg, A. L., \& Stein, C. H. (1996). Felt obligation towards parents in Mexican-American and AngloAmerican young adults. Journal of Social and Personal Relationships, 13, 457-471.

Fritz, M. S., \& MacKinnon, D. P. (2007). Required sample size to detect the mediated effect. Psychological Science, 18, 233-239.

George, L. (1996). Missing links: The case for a social psychology of the life course. The Gerontologist, 36, $248-255$.

George, L. (2007). Life course perspectives on social factors and mental illness. In W. R. Avison, J. D. McLeod, \& B. A. Pescosolido (Eds.), Mental health, social mirror (pp. 191-218). New York, NY: Springer.

Gruenewald, T. L., Mroczek, D. K., Ryff, C. D., \& Singer, B. H. (2008). Diverse pathways to positive and negative affect in adulthood and later life: An integrative approach using recursive partitioning. Developmental Psychology, 44, 330-343.

Haggerty, G., Blake, M., Naraine, M., Siefert, C., \& Blais, M. A. (2010). Construct validity of the Schwartz Outcome Scale-10: Comparisons to interpersonal distress, adult attachment, alexthymia, the five-factor model, romantic relationship length and ratings of childhood memories. Clinical Psychology and Psychotherapy, 17, 44-50.

Hayes, A. F. (2009). Beyond Baron and Kenny: Statistical mediation analysis in the new millennium. Communication Monographs, 76, 408-420.

Hooper, L. M., DeCoster, J., White, N., \& Voltz, M. L. (2011). Characterizing the magnitude of the relation between self-reported childhood parentification and adult psychopathology: A meta-analysis. Journal of Clinical Psychology, 67, 1-16.

Jurkovic, G. J. (1997). Lost Childhoods: The plight of the parentified child. New York, NY: Brunner/Mazel, Inc.

Jurkovic, G. J., \& Thirkield, A. (1998). Parentification Questionnaire (Available from G. J. Jurkovic, Department of Psychology, Georgia State University, University Plaza, Atlanta, GA 30303).

Jurkovic, G. J., Thirkield, A., \& Morrell, R. (2001). Parentification of adult children of divorce: A multidimensional analysis. Journal of Youth and Adolescence, 30, 245-257.

Kelley, M. L., French, A., Bountress, K., Keefe, H. A., Schroeder, V., Steer, K., . . Gumienny, L. (2007). Parentification and family responsibility in the family of origin of adult children of alcoholics. Addictive Behaviors, 32, 675-685.

Klein, D. N., Lewinsohn, P. M., Rohde, P., Seeley, J. R., \& Olino, T. M. (2005). Psychopathology in the adolescent and young adult offspring of a community sample of mothers and fathers with major depression. Psychological Medicine, 35, 353-365.

Lawton, L., Silverstein, M., \& Bengtson, V. (1994). Affection, social contact, and geographic distance between adult children and their parents. Journal of Marriage and the Family, 56, 57-68.

Linnen, A., ann het Rot, M., Ellenbogen, M. A., \& Young, S. N. (2009). Interpersonal functioning in adolescent offspring of parents with bipolar disorder. Journal of Affective Disorders, 114, 122-130.

Lye, D. N. (1996). Adult-child parent relationships. Annual Review of Sociology, 22, 79-102.

MacKinnon, D. P., Fairchild, A. J., \& Fritz, M. S. (2007). Mediation analysis. Annual Review of Psychology, 58, 593-614.

MacKinnon, D. P., Lockwood, C. M., \& Williams, J. (2004). Confidence limits for the indirect effect: Distribution of the product and resampling methods. Multivariate Behavioral Research, 39, 99-128.

McAuliffe, C. E. (2010). "It's about give and take": The importance of felt obligation in adolescence (unpublished doctoral dissertation). Bowling Green State University, Bowling Green, OH.

Miller, J. B., \& Lane, M. (1991). Relations between young adults and their parents. Journal of Adolescence, 14, 179-194.

Miller, J. B., \& Subblefield, A. (1993). Parental disclosure from the perspective of late adolescents. Journal of Adolescence, 16, 439-455.

Mowbray, C. T., Bybee, D., Oyserman, D., MacFarlane, P., \& Bowersox, N. (2006). Psychosocial outcomes for adult children of parents with severe mental illnesses: Demographic and clinical history predictors. Health and Social Work, 32, 99-108.

Mowbray, C. T., \& Mowbray, O. P. (2006). Psychosocial outcomes of adult children of mothers with depression and bipolar disorder. Journal of Emotional and Behavioral Disorders, 14, 130-142. 
Naus, M. J., Philipp, L. M., \& Samsi, M. (2009). From paper to pixels: A comparison of paper and computer formats in psychological assessment. Computers in Human Behavior, 25, 1-7.

Nicholson, J., Biebel, K., Hinden, B., Henry, A., \& Stier, L. (2001). Critical issues for parents with mental illness and their families. Rockville, MD: Center for Mental Health Services, Substance Abuse and Mental Health Services Administration.

Pickett, S. A., Cook, J. A., \& Cohler, B. J. (1994). Caregiving burden experienced by the parents of offspring with severe mental illness: The impact of off-timedness. The Journal of Applied Social Sciences, 18, 199-207.

Preacher, K. J., \& Hayes, A. F. (2008). Asymptotic and resampling strategies for assessing and comparing indirect effects in multiple mediator models. Behavior Research Methods, 40, 879-891.

Read, J. P., Farrow, S. M., Jaanimägi, U., \& Ouimette, P. (2006). Assessing trauma and traumatic stress via the Internet: Measurement equivalence and participant reactions. Traumatology, 15, 94-102.

Renk, K., Donnelly, R., Klein, J., Oliveros, A., \& Baksh, E. (2008). Cross-informant ratings of the emotional and behavioral functioning of college students. Journal of Youth and Adolescence, 37, 193-210.

Roberts, R. E. L., \& Bengtson, V. L. (1996). Affective ties to parents in early adulthood and self-esteem across 20 years. Social Psychology Quarterly, 59, 96-106.

Schulenberg, J., O’Malley, P. M., Bachman, J. G., \& Johnston, L. D. (2005). Early adult transitions and their relation to well-being and substance abuse. In R. A. Setterson, F. F. Furstenberg, \& R. G. Rumbat (Eds.), On the frontier of adulthood: Theory, research, and public policy. Chicago, IL: The University of Chicago Press.

Smith, M. J., \& Greenberg, J. S. (2008). Factors contributing to the quality of sibling relationships for adults with schizophrenia. Psychiatric Services, 59, 57-62.

Sobel, M. E. (1982). Asymptotic confidence intervals for indirect effects in structural equations models. In S. Leinhart (Ed.), Sociological methodology 1982 (pp. 290-312). San Francisco, CA: Jossey-Bass.

Sobel, M. E. (1986). Some new results on indirect effects and their standard errors in covariance structure models. In N. Tuma (Ed.), Sociological methodology 1986 (pp. 159-186). Washington, DC: American Sociological Association.

Stein, C. H. (1992). Ties that bind: Three studies of obligation in adult relationships with family. Journal of Social and Personal Relationships, 9, 525-547.

Stein, C. H. (2009). "I owe it to them": Understanding felt obligation towards parents in adulthood. In K. Shifren (Ed.), How caregiving affects development: Psychological implications for child, adolescent, and adult caregivers (pp. 119-145). Washington, DC: American Psychological Association.

Stein, C. H., Wemmerus, V. A., Ward, M., Gaines, M. E., Freeberg, A. L., \& Jewell, T. C. (1998). "Because they're my parents": An intergenerational study of felt obligation and parental caregiving. Journal of Marriage and the Family, 60, 611-622.

van Wel, F., ter Bogt, T., \& Raaijmakers, Q. (2002). Changes in the parental bond and the well-being of adolescents and young adults. Adolescence, 37, 317-333.

Watson, D., \& Tellegen, A. (1985). Toward a consensual structure of mood. Psychological Bulletin, 98, 219-235.

Watson, D., Wiese, D., Vaidya, J., \& Tellegen, A. (1999). The two general activation systems of affect: Structural findings, evolutionary considerations, and psychobiological evidence. Journal of Personality and Social Psychology, 76, 820-838.

Williams, A. S. (1998). A group for the adult daughters of mentally ill mothers: Looking backwards and forwards. British Journal of Medical Psychology, 71, 73-83.

Williams, O. B., \& Corrigan, P. W. (1992). The differential effects of parental alcoholism and mental illness on their adult children. Journal of Clinical Psychology, 48, 406-414.

Wintre, M. G., Yaffe, M., \& Crowley, J. (1995). Perception of parental reciprocity scale (POPRS): Development and validation with adolescents and young adults. Social Development, 4, 129-148.

Young, J. L., Waehler, C. A., Laux, J. M., McDaniel, P. S., \& Hilsenroth, M. J. (2003). Four studies extending the utility of the Schwartz outcome scale (SOS-10). Journal of Personality Assessment, 80, 130-138.

Youniss, J. (1980). Parents and peers in social development. Chicago, IL: The University of Chicago Press.

Youniss, J., \& Smollar, J. (1985). Adolescent relations with mothers, fathers, and friends. Chicago, IL: The University of Chicago Press. 